\title{
Investigation and Research on the Current Situation of Minority Language Ecology in the Western Yunnan Border
}

\author{
Siying Duan \\ Baoshan University, Baoshan, Yunnan, 678000, China
}

Keywords: Western Yunnan border; ethnic minorities; native nationalities; language ecology.

\begin{abstract}
In this paper, through investigating and analyzing the language ecology of ethnic minorities such as Achang, Blang, Nu, De'ang and native nationalities such as Lahu, Va, Lisu, Dai, Bai and Yi in the western Yunnan border, the current situation and development trend of the language inheritance and application pf the ethnic minorities in western Yunnan are known, and then some rough suggestions for continuous construction of harmonious language ecosystem in western Yunnan are proposed.
\end{abstract}

\section{Introduction}

One of the highlights of the Amendment of the Constitution of the People's Republic of China voted at first session of the $13^{\text {th }}$ National People's Congress is "Putting the ecology into the Constitution". This move has brought the construction of ecological civilization to an unprecedented height and laid a solid foundation for building a beautiful China. Building a good language ecology is not only the need of ecological civilization construction, but also an important component of ecological civilization construction. There are many ethnic groups in the ethnic minority areas in the western Yunnan border, and the national languages are colorful. The existence of unique nationalities, ethnic minorities and cross-border nationalities has formed a unique language resource in the western Yunnan border, and differs the language ecology of the minority areas in the western Yunnan border from that of other regions. The investigation and study of minority language ecology in this area can comprehensively understand the current situation and development trend of language application of ethnic minorities in this area, which is conducive to promoting friendly exchanges between the various ethnic groups in the western Yunnan border, improving the level of communicative exchanges between the various nationalities, building a harmonious language environment in the western Yunnan border, and promoting the unity of all ethnic groups and economic and cultural development in the area of western Yunnan border.

\section{Current Situation of Minority Language Ecology in the Western Yunnan Border}

\subsection{The Mother Tongue Inheritances of Most Ethnic Minority are Stable}

Through investigations and interviews of different ethnic minority respondents, it is found that the vast majority of ethnic minorities in the western Yunnan border have better inherited their mother tongues. This is related to the special geographical position of western Yunnan border, the lag of local economic development, the loose national policy of the country, and the emotions of ethnic minorities, etc. Most of the ethnic minorities in the western Yunnan border live in remote mountainous areas, and they have a distribution pattern of "big mixed, small settlements". The frequency of exchanges between ethnic minorities and the outside world is much lower than that of economically developed areas, and except from going out to study and work, most ethnic minorities here rarely have the opportunity to go out from their hometowns, which fundamentally guarantees the stable environment of mother tongue inheritance of ethnic minorities. Coupled with the enthusiasm of the country's loose language policy and the drive of national sentiment, many ethnic minorities take 
responsibility for inheriting and using their own national language, thus ensuring the stable inheritance and application of their mother tongues. Of course, due to the constraints of population, language environment, economic development and other conditions, there are also some changes in the inheritance and application of mother tongue, and individual ethnic minorities even lose their mother tongues. According to the survey, the proportion of respondents in Lahu, Va, Lisu, Dai and Bai nationalities who can hear and speak their mother tongues achieves more than $90 \%$, and the master of mother tongue for the nationalities with less population is not optimistic. The ethnic minorities such as the Blang, De'ang, and Achang nationalities involved in the investigation have experienced the crisis of mother tongue inheritance in different degrees.

\subsection{All Ethnic Minorities Have Difference Levels of Language Sharing}

There are many kinds of minority nationalities in the western Yunnan border, and the multi-ethnic mixed habitation and intermarriage among different nationalities are the characteristics of the ethnic distribution in Western Yunnan. Under the background of multi-ethnic mixed habitation, Chines dialect has become the common language of people in many ethnic minority communities and mixed habitations; therefore, the language sharing phenomenon of all ethnic minorities is colorful. In the ethnic mixed areas, the phenomenon that ethnic minorities speak three or more languages is very common. In Tu'e Village, Lanping County, Nujiang Prefecture, many residents of $\mathrm{Nu}$, Bai, Lisu and Han nationalities can flexibly switch to Nu Language, Bai Language, Lisu Language and Chinese dialects according to the scene in their daily communications and exchanges, and there are many "four-language" people in the village. Some families are made up of three or four nationalities, so the languages inside the family have become rich and colorful, in addition to Putonghua, which is taught in school, the children in such a family can speak five languages. This is a higher level of language sharing, and it is also a valuable language ecological wealth of the whole western Yunnan. In Renshan Village, Yunlong County, there are also many people who can speak the "three languages" of Achang, Bai and Chinese dialects at the same time. In Dazhong Village, Longyang District, many people of De'ang nationalities can also communicate with each other in De'ang Language, Dai Language and Chinese dialects. In Nuozhang Village of Cangyuan County, due to the population of Lahu nationality is the absolute majority, the Lahu Language has become a strong language in the village, so most of the Va people in the village can communicate with the Lahu nationality in Lahu Language, but only a few Lahu people can communicate with the Va nationality in Va Language, in addition, Chinese dialects are often spoken by residents when they go out to market to buy and sell goods, to find employment in hospitals and to handle affairs in government departments; therefore, Va adults in the village can generally speak both Va Language, Lahu Language and Chinese dialects, but people of Lahu nationality can only generally speak both Lahu Language and Chinese dialects. Others such as the Lisu people in Sudian Village, Sudian Township, Yingjiang County, they can speak both Lisu Language and local dialects, and the Dai people in Xijia Village, Mangkuan Township, Longyang District can speak both Dai Language and Chinese dialects, while the Lisu people can generally speak both Dai Language, Lisu Language and local Chinese dialects. The Achang people in Langguang Village, Husa Township, Longchuan County speak both Achang Language and Chinese dialects, and it is also prominent for Lisu people speak both Lisu Language and Chinese dialects.

\subsection{Harmonious Coexistence of Minority Languages and the Common Language of the Country}

The harmony of minority languages in the western Yunnan border is relatively high. First of all, ethnic minorities in the western Yunnan border have always attached great importance to national unity, so the harmony of ethnic relations naturally contributes to the harmonious relationship of language. Language is an important feature of a nation, which is closely related to national consciousness and national sentiment, so the relationship between nationalities has a direct impact on the relationship between languages. If the relationship between nationalities is good, the relationship between languages is also good; otherwise, if the relationship between nationalities is not good, the 
relationship between languages will be negatively affected ${ }^{[1] \mathrm{p} 15}$. Ethnic minorities in the western Yunnan border not only get along well with each other from generation to generation, but also hold a more open attitude towards intermarriage; therefore, intermarriage between ethnic nationalities occurs now and then. Especially in multi-ethnic mixed habitations, sometimes there are four or five ethnic minorities in a family, and four or five nationalities in a village is even more common. Friendly exchanges, mutual learning and tolerance among different nationalities have formed a good situation of national harmony, thus promoting the linguistic harmony of all nationalities. Secondly, ethnic minorities in western Yunnan border have a more open and inclusive language concept. They love their own national language, respect the language of other nationalities and Chinese, are willing to learn other minority languages and Chinese, and are willing to communicate with people of other ethnic nationalities in other minority languages and Chinese dialects. Therefore, in the multi-ethnic areas of western Yunnan border, when different ethnic minorities meet with each other, the interesting scenes often occur that $\mathrm{Nu}$ people greet Bai people in Bai Language and Bai people answer Nu people in Nu Language; Jingpo people greet Dai people in Dai Language and Dai people answer Jinpo people in Jingpo Language. Of course, the phenomenon often occurs that different nationalities don't understand each other when they meet with each other, then at this time, they will naturally choose the local Chinese dialect as the language of communication. It is precisely because of the great national integration of the "one family" ethnic minorities in the western Yunnan border and the open and inclusive nation concept of the ethnic minorities, rich and colorful ethnic resources and language resources and harmonious language situation in the western Yunnan border have been created. Thirdly, the rapid development of the modern society has promoted the language harmony of the minority nationalities in the western Yunnan border. Language harmonious is not only the development needs of all ethnic groups, but also the needs of social development. Especially in the modern society, with the rapid development of science and technology, the exchanges and cooperation among ethnic minorities are growing, and their communication and cooperation with the outside world are also increasing. In order to realize the leap-forward development of ethnic groups as soon as possible, people need a peaceful and stable social environment, and need friendly cooperation among ethnic groups. All factors that are not conducive to social harmony are not accepted by people. National harmony and language harmony have become the common aspiration of the people in all nationalities ${ }^{[2] \mathrm{p} 94}$. The ethnic unity and language harmony in the western Yunnan border are also conducive to promote the stability and harmony of the western Yunnan border.

\subsection{Endangered Situation of Languages for the Minorities with Less Population in the Western Yunnan Border is Obvious}

As we can see that the mother tongue inheritance of the minorities is generally stable, language resources are rich and languages are harmonious and stable in the western Yunnan border, at the same time, there are also some potential language ecological crisis worthy of our attention, especially the language endangered reality of the minorities with less population in western Yunnan border cannot be ignored. In a special survey of the language use of Blang people in Hazhai Village, the research group found that there are 802 Blang people, accounting for $65.31 \%$ of the total population of the whole village, which can be said that this village is a Blang village, but nearly all of the young children of Blang in the entire village can no longer speak Blang Language. While more than half of the younger generation (21-35 years old) of the Blang nationality cannot speak Blang Language, and some young people can understand Blang Language but do not willing to speak, and some say that there is not much to understand. Nearly half of the middle-aged generation (36-55 years old) of Blang people are basically proficient or can only understand but cannot speak, while only the elderly(over 56 years old) of Blang respondents are all proficient in Blang Language ${ }^{1}$. The intergenerational weakening or even break of the mother tongue inheritance shows that the vitality of Blang mother tongue in Hazhai Village is gradually weakening, and if the lack of vitality of the mother tongue is not

\footnotetext{
${ }^{1}$ See the results of the project: Duan Siying, LiuSaimei and Chen Zhiyue. Investigation and Analysis of Language Switching Situation on the Mulaoyuan Blang People in Shidian County[J]. Xiaozuojia Xuankan, 2018(03):4-5.
} 
effectively controlled or further evolved, it will inevitably lead to the endangerment of the language. Therefore, it is necessary and urgent to strengthen the linguistic investigation and research on the minorities with less population in the western Yunnan border, and develop effective protection strategies to effectively mitigate the endangered languages of ethnic minorities with less population.

\section{Suggestions for Constructing Harmonious Language Ecology in the Minority Areas in the Western Yunnan Border}

\subsection{Vigorously Promote the Strategy of Language Poverty Alleviation in the Western Yunnan Border, and Construct a Harmonious Language Ecological Environment in the Western Yunnan Border}

Most of the minority inhabited and mixed areas in the western Yunnan border are located in remote cold and high mountain areas and semi-mountainous areas with bad transportation and underdeveloped economy. Therefore, the minority nationalities living here are generally less educated and have a weak ability to acquire knowledge and information, thus the ability and level of most minority nationalities to speak the common language of the country and other national languages are relatively weak. Therefore, our country has put forward some concepts such as "The first of poverty alleviation is wisdom alleviation.", and "By enhancing the multi-lingual competence of the poor people, their basic qualities, communicative competence and abilities to acquire knowledge and information will be improved, thus promoting their concept, knowledge, intelligence and development ability to get rid of poverty.” ${ }^{3] \mathrm{p} 1}$, etc. And some scholars have also pointed out that the lack of better language learning environment is an important factor to restrict the minority language learning and use in poverty-stricken areas ${ }^{[4] \mathrm{p} 153}$. Poverty alleviation through language helps the precise poverty alleviation in the minority areas of western Yunnan border, which undoubtedly can speed up the pace of poverty alleviation in this area, can create a better atmosphere for language learning and use, and is conducive to building a more harmonious language ecological environment in this region.

\subsection{Properly Handle the Relationship between Minority Languages and National Common Language, Maintain the Linguistic Pluralism of minority areas in western Yunnan border}

There are many ethnic nationalities in the western Yunnan border. Among the 56 ethnic groups in the country, there are 26 ethnic groups living on the lot land of West Yunnan. In these ethnic groups, there are many “directly-entering-socialism ethnic groups” such as Dulong, De’ang, Jinuo, Nu, Blang, Jingpo, Va, Lisu, Lahu and so on, so the national culture is colorful. In addition, this area is bordered by Burma, Laos and Vietnam, which has an obvious advantage of international location. Such special geographical environment determines its special language situation and language diversity. Due to the differences in living habits and national beliefs, various ethnic minorities naturally form different national cultures, which are reflected in their languages are their own advantages and own characteristics. The differences between languages and cultures of different nationalities create the situation of language pluralism. Therefore, only by encouraging and guiding all ethnic groups to respect the characteristics and differences of other national languages and national common language, can they be inspired to accept the diversity of languages and cultures with great enthusiasm and

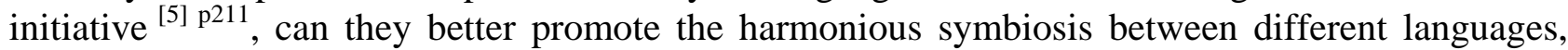
realize the true language equality, and then promote the formation of a harmonious language ecology.

\subsection{Continuously Attach Importance to the Protection and Rescue of Endangered Minority Languages, Enhance the Language Vitality of Endangered Minority Languages}

Scientific protection of languages of all nationalities, and emphasis on the protection and rescue of endangered languages are important contents of language ecological construction. There are many minority nationalities in the western Yunnan border, among which the languages of the Blang, $\mathrm{Nu}$ and De'ang nationalities are endangered. The relationship between language and culture is 
self-evident, and the endangerment of language will directly lead to the endangerment and even extinction of national culture. The protection of endangered languages is not only related to national unity and the harmonious development of the country, but also related to the diversification, ecological and healthy development of national cultures. Therefore, it is urgent to protect and rescue the endangered languages, whether from the perspective of language and national conditions, or from the perspective of language policy. For the western Yunnan border with many ethnic groups and mixed ethnic inhabitations, the whole efforts of the society should be given to give advice and suggestions in protecting endangered ethnic languages in this region, so as to save these endangered ethnic languages, enhance the language vitality of the endangered ethnic minorities, and maintain the cultural ecology of ethnic minority areas.

\section{Conclusion}

The area of western Yunnan border has a good foundation of language ecology. For example, the mother tongue inheritances of most ethnic minorities are stable, multi-ethnic mixed areas live in harmony with each other, and ethnic minorities generally have developed inclusive language concepts. However, there are also language ecological crises such as the mother tongue of ethnic minorities are not active enough, poor national language inheritance, poor mother tongue education, poor promotion and popularization of national common language characters, and endangered language of individual nationalities with less populations, etc. Under the background of the rapid development of the modern economy, the living conditions and ideas of ethnic minorities will undergo rapid changes, and the original language ecology will also encounter challenges. Therefore, no matter from the perspective of constructing national ecological civilization, or from the perspective of sustainable development of language culture in the minority areas in the western Yunnan border, it is of great significance to attach importance to the language ecology construction of ethnic minority areas in the western Yunnan border.

\section{References}

[1] Dai Qingxia. Language and Nationality, Beijing: Central University for Nationalities Press, 1994:15.

[2] Qiao Xiang, Yu Jinzhi. The Language Harmony of Multi-ethnic Groups in the Yanyuan County, Sichuan Province, Journal of the Central University for Nationalities (Humane and Social Sciences Edition), 2016(06):89-94.

[3] Shi Lin. Strategies for Popularizing and Deepening the National Common Language in Minority Areas from the Perspective of Targeted Poverty Alleviation, Social Scientist, 2018(04): 150-156.

[4] Wang Yaxuan. Construction of Language Ecological Environment in Minority Mixed Areas under Ecological Linguistics, Guizhou Ethnic Studies, 2018(05):210-214. 